\title{
Notes
}

\section{Managing In The 1990s - Freeing the EnTrepreneurial Spirit}

\author{
Stanley C. Ross \\ State University of New York \\ Brockport, New York
}

\section{Integration of the United States into the World Economy}

Successful management is critical in today's business climate, because large organizations no longer can consider the United States as their private domain nor dominate individual markets with little to no competition. Global interdependencies are accelerating the integration of the United States economy with the world economic community. The momentum means that turning back is not a realistic alternative without seriously impairing the domestic economy [1].

To remain competitive using a global strategy demands that products meet the needs of users, product quality achieves the performance standards expected by buyers, and costs are contained in order to offer competitive prices. To achieve these ends and to remain competitive requires a radical shift in the thinking about strategy (how to compete) and strategy implementation (organizing to enhance the firm's competitive position). The purpose of this paper is to address the management problems of large organizations $^{1}$ and to suggest a resolution to the problems by recasting the large organization as a free market system.

\section{Problems in Managing Large Organizations}

Like society, an organization is a collection of people interacting for the benefit of themselves and the collective whole. As the society within the organization expands, greater effort is expended to control the actions of its members with the objective of coordinating all activities. Control gains in importance as the organization attempts to maximize economic returns through intensive coordination of effort, a natural response when managing a large enterprise. The result is that control activities begin to dominate organizational decisions, and control itself becomes problematic due to the enormity of the task and resistance from members of the organization [2].

Control is of less importance in the design and ongoing function of the management systems initially; but as the organization expands and adds employees, there seems to be a gradual but undeniable turn away from a goal orientation. Two explanations are suggested to account for the change in emphasis. First, to better manage large numbers of employees in an increasingly diverse operation, firms promote

${ }^{1}$ A large organization is defined as an organization with 2,000 or more employees. 
conformance among employees in order to simplify management requirements. Second, expansion activities lead to growth which only exacerbates the difficulty in controlling the "society" within the organization. Initially the organization adds support personnel and develops more elaborate management systems to facilitate control. The failure to achieve the desired ends results in a shift away from growth opportunities because of the control problems associated with growth management.

For large organizations, internal harmony and consistency have become the important goals. Innovation strains management systems' capacity to control the behavior of individuals and ultimately the entire organization. Harmony and innovation are seen as mutually exclusive; and though a firm might aspire to the appeal of being a known innovator, it cannot cope with a catalytic phenomenon that is destabilizing, no matter how great the appeal [3].

\section{The Paradox}

Organizations advocating growth oriented goals and strategies will be encouraging change within the organization. According to general systems theory, change in one part of the organization affects all the other parts. Goals promoting growth, defined here as leading to economic gains, are necessary if the organization is to ward off atrophy by adapting to trends in the marketplace. Promoting growth leads to a paradox; because change disrupts relationships and established norms, leading to resistance. The emphasis on maintaining order concomitant with the inclination to resist change by individuals results in organizational resistance. The large organization faces two difficult and mutually exclusive choices. It can promote growth, which disrupts; or stability can be emphasized, which gradually leads to declining growth patterns. Unable and seemingly unwilling to accept this contradiction, the large organization's strategic agenda is to promote growth while maintaining stable operations. The goals and strategies may appear to emphasize growth, but the organization has no intention of following through (i.e., the hidden agenda). This inconsistency reflects an organization suffering from cognitive dissonance, exhibiting behavior consistent with its basic beliefs [4]. In this case, maintaining stability is the primary goal because change is too disruptive and unsettling. Since growth and stability are incompatible, the large organization chooses stability because of the difficulty in creating management systems that can support both concurrently.

The emphasis on stability as the central focus gives short shrift to innovative behavior, ultimately leading to the demise of growth strategies that promote innovation.

\section{Resolving the Paradox}

Modeling the large organization as a free market system frees the entrepreneurial spirit of business units from the straightjacket imposed by the controlling corporate parent. The organization as a free market system should function like one, with the flow of resources moving to the most productive units offering the greatest Rate of Return ROR. The impetus and commitment for change in strategy and strategy 
implementation is derived from the requirement that the competitive position must be improved. The corporate growth strategy, in effect, is an investment strategy. The goal is to maximize the (ROR) on the investment. The business units comprising the holdings represent an investment portfolio. Performance of the organization is evaluated by the portfolio's ROR. Units would be added or dropped contingent on their actual contribution or potential to support the investment strategy. The allocation of resources would be based on unit performance and future prospects for contributing to economic growth and ROR. Units should be able to operate in any industry and market because operational compatibility with the parent is no longer axiomatic other than to support the investment strategy.

Tensions between the parent and business units will exist over the allocation of resources which are influenced by the investment strategy of the firm. However, the parent's control over resources and business units' control over their operations will force each into mutually beneficial agreements. The corporate and business strategies will be linked because providing capital to business units willing to pay a higher price will enable the parent to achieve its ROR goal. Business units exercise a greater commitment to productivity and efficiency because of the need to demonstrate real economic gains. Improved performance can lead to a higher ROR, enabling the business units to gain greater access to capital and more control over the management of their operations. Acquisition policies are derived from the investment strategy. Divestiture occurs when a unit is unable to support the investment strategy according to specific performance criteria.

The organization would be designed as a holding company. Operating autonomously allows each business unit to develop an organizational design and operating policies to address the competitive conditions in the markets in which they compete. By maximizing the autonomy of business units and minimizing parental interference in day-to-day issues, business units' flexibility in making strategic and operating decisions will be strengthened [5].

Elaborate management systems are no longer needed to facilitate control. Performance control measures, derived from the parent's investment strategy and investment goals, will form the basis for assessing the performance of the firm. Business units will respond in kind by utilizing performance measures; because survival and growth are now linked to access to capital, which is tied to performance.

A complication for many large organizations is business units which sell all or most of their outputs internally. Too often transfer price agreements have not been established or are dictated by the parent. The supplier's performance will often be under reported because the prices are below the market rates, while the buyer's performance may look too good due to a deflated cost structure. Under the proposed model, the buyer and seller would be able to negotiate with any party which offers the optimal deal, to include market prices. Both buyer and seller will have to adhere to market standards. Each becomes performance driven.

Economies of scale have often been used to justify uniting many businesses under one corporate roof, and closely integrated. The focus on economies of scale shifts the emphasis towards efficiency, with goals defined as cost-reducing targets. Units 
are organized by competitive distinctiveness in order to provide a common frame of reference. The goals and strategy are derived from their respective strengths and environmental circumstances and competitive opportunities. Organizing around a unique characteristic(s) tends to diseconomies of scale. However, higher cost, rather than a negative, are offset by the increased motivation to expand in order to reduce operating costs. Reliance on efficiency measures over the long run are inadequate in generating satisfactory performance or growth because of the diminishing returns associated with cost-reduction activities.

\section{Summary}

In an organization modeled on the free market system, the corporate parent and the business units better their productivity and become more efficient to attract the resources needed to support a growth strategy. Individual business units are able to identify their own goals and strategies as well as develop the operational plans for implementing the strategies. Resistance to the changes is defused because the parent focuses on performance and seeks sustained economic growth instead of homogenizing the organization under the guise of promoting synergy [6].

\section{References}

1. Keane, John. "Focusing on the Corporate Future: Not a Trivial Pursuit." Business Horizons (January-February 1987), p. 31.

2. Perror, Charles. Complex Organizations. 3rd Edition, New York: Random House (1986), pp. 178-257.

3. Waterman, Jr., Robert. The Renewal Factor: How the Best Get and Keep the Competitive Edge. New York: Bantam (1987), p. 112; Y. Allarie and M. Firsirotu, "How to Implement Radical Strategies in Large Organizations," Sloan Management Review (Spring 1985), p. 19; H. Igor Ansoff, "Strategic Management of Technology," Joumal of Business Strategy, Vol. 7, No. 3 (Winter 1987), p. 38.

4. Kimble, Gregory A. and Germezy, Norman. Principles of General Psychology. 2nd Edition, New York: The Ronald Press Co. (1963), pp. 591-594.

5. Prahalad, C.K. and Hamel, Gary. "The Core Competence of the Corporation." Harvard Business Review (May-June 1990), pp. 79-91

6. Fama, Eugene F. "Agency Problems and the Theory of the Firm." Journal of Political Economy, Vol. 88 (1980), pp. 288-307. 